\title{
POLÍTICAS DE INCLUSÃO E AS RECOMENDAÇÕES DOS ORGANISMOS INTERNACIONAIS PARA O ENSINO MÉDIO E SUPERIOR NO BRASIL
}

\author{
Rosemary Roggero (UNINOVE)* \\ Aline Sarmento Coura Rocha (UNINOVE)** \\ Geuid Cavalcante da Silva Filho (UNINOVE)***
}

\begin{abstract}
RESUMO
O presente trabalho aborda as políticas educativas de inclusão no âmbito do ensino médio e superior, no período de 2003 a 2014. O problema de investigação consiste em saber qual a resposta brasileira às recomendações internacionais em relação à inclusão de parcelas da população jovem no ensino médio e superior. O objetivo é analisar a influência das recomendações dos organismos internacionais sobre as políticas educacionais para os ensinos médio e superior brasileiros, na perspectiva de inclusão dos jovens em processos de escolarização e profissionalização. Para isto, realizamos um recorte histórico das políticas educacionais para os ensinos médio e superior nos governos de Luís Inácio Lula da Silva (2003-2010) e Dilma Rousseff (20112014); analisamos os principais documentos com recomendações dos organismos internacionais para o ensino médio e o ensino superior; e investigamos a influência das recomendações dos organismos internacionais sobre essas políticas educacionais, bem como a resposta a essas recomendações. A metodologia utilizada foi a pesquisa bibliográfica e documental. Adotamos como referencial teórico a Teoria Crítica da Escola de Frankfurt.
\end{abstract}

Palavras-chave: Políticas educativas. Ensino médio e ensino superior. Organismos internacionais.

\section{ABSTRACT \\ INCLUSION POLICIES AND THE RECOMMENDATIONS OF THE INTERNATIONAL ORGANIZATIONS FOR MIDDLE AND HIGHER EDUCATION IN BRAZIL}

The present study deals with the educational policies of inclusion in the scope of secondary and higher education, from 2003 to 2014. The research problem consists of knowing the Brazilian response to the international recommendations regarding the

\footnotetext{
* Doutora em Educação pela Pontifícia Universidade Católica de São Paulo (PUC-SP). Docente e pesquisadora nos Programas de Pós-Graduação em Educação (mestrado e doutorado) e em Gestão de Projetos Educacionais (mestrado profissional) da Universidade Nove de Julho (UNINOVE). E-mail: roseroggero@uol.com.br

** Doutoranda em Educação pela Universidade Nove de Julho (PPGE/UNINOVE). Mestre em Educação pela Universidade Nove de Julho (UNINOVE). Bolsista da Coordenação de Aperfeiçoamento de Pessoal de Nível Superior (CAPES). E-mail: alinecourasj@gmail.com

${ }^{* * *}$ Mestrando em Educação pela Universidade Nove de Julho (UNINOVE). Técnico em Assuntos Educacionais no Instituto Federal de Educação, Ciência e Tecnologia do Piauí. E-mail: geuidfilho@ifpi.edu.br
} 
inclusion of plots of the young population in high school and higher. The objective is to analyze the influence of the recommendations of the international organisms on the education policies for the Brazilian high and higher education, with a view to include the young people in the processes of schooling and professionalization. For this, we made a historical cut of educational policies for secondary and higher education in the governments of Luís Inácio Lula da Silva (2003-2010) and Dilma Rousseff (20112014); we analyzed the main documents with recommendations from international organizations for high school and higher education; and we investigate the influence of the recommendations of the international organisms on these educational policies as well as the response to these recommendations. The methodology used was the bibliographical and documentary research. We adopted as theoretical reference the Critical Theory of the Frankfurt School.

Keywords: Educational policies. High school and higher education. International organizations.

\section{RESUMEN}

\section{POLÍTICAS DE INCLUSIÓN Y RECOMENDACIONES DE LOS ORGANISMOS INTERNACIONALES PARA LA ENSEÑANZA MEDIO Y SUPERIOR EN BRASIL} El presente trabajo aborda las políticas educativas de inclusión en el ámbito de la enseñanza media y superior en el período de 2003 a 2014. El problema de investigación consiste en saber cuál es la respuesta brasileña a las recomendaciones internacionales en relación a la inclusión de parcelas de la población joven en la enseñanza media y superior. El objetivo es analizar la influencia de las recomendaciones de los organismos internacionales sobre las políticas educativas para la enseñanza media y superior brasileños, en la perspectiva de inclusión de los jóvenes en procesos de escolarización y profesionalización. Para ello, realizamos un recorte histórico de las políticas educativas para la enseñanza media y superior en los gobiernos de Luís Inácio Lula da Silva (2003-2010) y Dilma Rousseff (2011-2014); analizamos los principales documentos con recomendaciones de los organismos internacionales para la enseñanza media y la enseñanza superior; e investigamos la influencia de las recomendaciones de los organismos internacionales sobre estas políticas educativas, así como la respuesta a estas recomendaciones. La metodología utilizada fue la investigación bibliográfica y documental. Adoptamos como referencial teórico la Teoría Crítica de la Escuela de Frankfurt.

Palabras clave: Políticas educativas. Enseñanza media y enseñanza superior. Organismos internacionales.

\section{Introdução}

Nada novo sob o sol. A educação, entre outros direitos sociais, continua a ser negligenciada, mesmo que o discurso oficial, desde a década de 1990, procure escamotear a realidade e dissolver a tensão entre os interesses econômicos dominantes e as necessidades da população. Contudo, há alguns avanços. E, nesse sentido, questionamos: qual a resposta brasileira às recomendações internacionais em relação à inclusão de parcelas da população jovem no ensino médio e superior?

No Brasil, um dos bordões mais comuns é que é preciso investir em educação, e a análise dos indicadores financeiros mostra que o país avançou muito em relação ao gasto público nessa área, per- 
mitindo atingir novos patamares de investimentos ao longo do período 2000-2013. Todavia, o que pode ser observado é que o aumento dos recursos, mesmo que de maneira oscilante, não tem permitido vislumbrar proporcional melhora no desempenho qualitativo.

Ao abordar as políticas educativas de inclusão no âmbito do ensino médio e superior, no período de 2003 a 2014, propomo-nos a analisar neste artigo a influência das recomendações dos organismos internacionais sobre as políticas educacionais para os ensinos médio e superior brasileiros, na perspectiva de inclusão dos jovens em processos de escolarização e profissionalização.

Para tanto, analisamos os principais documentos com recomendações dos organismos internacionais e realizamos um levantamento das políticas educacionais nos governos de Luís Inácio Lula da Silva (2003-2010) e Dilma Rousseff (2011-2014) para o ensino médio e para o ensino superior. Posteriormente, nos detemos na investigação da influência das recomendações dos organismos internacionais sobre essas políticas educacionais como respostas àquelas.

\section{Políticas educativas para o ensino médio e a influência dos organismos internacionais}

O Brasil teve, em 2016, segundo dados da Sinopse Estatística da Educação Básica, elaborada pelo Instituto Nacional de Pesquisas Educacionais Anísio Teixeira (INEP), 8.133.040 estudantes matriculados no ensino médio. Na educação profissional, as matrículas chegaram a 1.859 .940 alunos, boa parte delas em cursos de formação técnica de nível médio (INSTITUTO NACIONAL DE ESTUDOS E PESQUISAS EDUCACIONAIS ANÍSIO TEIXEIRA, 2017).

A observação dos dados permite perceber que houve uma ampliação considerável na quantidade de pessoas inseridas na escolarização que visa à preparação para a vida profissional, seja por meio da formação no ensino médio, na educação profissional, ou a partir da oferta de ambas com algum tipo de articulação.

A oferta de cursos que unem a formação geral no ensino médio com a formação técnica e profissional parece ter sido marcante nos mandatos de Luís Inácio Lula da Silva (2003-2006 e 2007-2010) e de Dilma Rousseff (2011-2014). Uma opção que pode estar relacionada com a própria visão de formação adotada por esses governos, em razão de elementos político-ideológicos e de projeto de sociedade, resultado, entre outras coisas, das influências de intelectuais e grupos que tiveram suas vozes ouvidas por esses governos. E que também representaram uma resposta às recomendações de organismos internacionais para as políticas educacionais, com destaque para o papel representado pela Organização das Nações Unidas para a Educação, Ciência e Cultura (UNESCO), como se verá adiante.

Uma das principais referências para a implementação das políticas educacionais sobre as quais discutiremos, durante os governos Lula (20032010) e Dilma (2011-2014), teria sido o Marco de Ação de Dakar - documento que resultou de um compromisso dos governos de países reunidos no Fórum Mundial de Educação, realizado em Dakar (Senegal) no ano 2000. Os países participantes do encontro se comprometeram a alcançar os objetivos e as metas do Educação Para Todos (EPT) para seus cidadãos. No compromisso de Dakar foi reafirmada a visão da Declaração Mundial de Educação para Todos, produzida em Jomtien (Tailândia), em 1990.

A avaliação das ações implementadas entre os anos de 1990 e 2000, no texto do Marco de Ação de Dakar, defende que houve progresso significativo em muitos países, mas reconhece a permanência de muitos desafios, no que se refere à oferta de educação para todos. E, nesse sentido, o documento indica, especialmente, que a conquista de qualidade de aprendizagem ainda não havia sido alcançada e que permanecia insatisfatória a aquisição de valores e habilidades humanas que pudessem satisfazer as aspirações e necessidades dos indivíduos e das sociedades (ORGANIZAÇÃO DAS NAÇÕES UNIDAS PARA A EDUCAÇÃO, A CIÊNCIA E A CULTURA, 2001).

Outra deficiência apontada no documento de Dakar diz respeito ao acesso às técnicas e conhecimentos necessários a jovens e adultos, para encontrar emprego remunerado e participar plenamente da sociedade. Essa deficiência foi um dos elementos que contribuiu para que fosse assumido o seguinte objetivo: "assegurar que as 
necessidades de aprendizagem de todos os jovens e adultos sejam atendidas pelo acesso equitativo à aprendizagem apropriada e às habilidades para a vida"(ORGANIZAÇÃO DAS NAÇÕES UNIDAS PARA A EDUCAÇÃ̃O, A CIÊNCIA E A CULTURA, 2001, p. 8-9).

Para o atendimento desse objetivo, a todos os jovens deveria ser dada a oportunidade de obter conhecimento e desenvolver valores, atitudes e habilidades que lhes possibilitassem desenvolver suas "capacidades para o trabalho, para participar plenamente de sua sociedade, para deter o controle de sua própria vida e para continuar aprendendo" (ORGANIZAÇÃO DAS NAÇÕES UNIDAS PARAA EDUCAÇÃO, A CIÊNCIA E A CULTURA, 2001, p. 19)

Quais teriam sido, diante dessas recomendações, as políticas educacionais implementadas no Brasil entre 2003 e 2014 que poderíamos considerar como respostas ao objetivo descrito acima (ainda que não possamos restringir a essas recomendações o fator que fez com que esses governos elaborassem e implementassem tais políticas)?

No primeiro caso, do governo de Luís Inácio Lula da Silva, à frente da presidência do Brasil por dois mandados entre os anos de 2003 e 2010 , destacamos como políticas que entendemos terem sido respostas do país às recomendações da UNESCO, em termos de inclusão dos jovens em processos de escolarização e profissionalização, a expansão da Rede Federal de Educação e o aumento das matrículas na educação profissional técnica de nível médio, incluindo a educação de jovens e adultos.

De maneira geral, houve um aumento nas matrículas na educação profissional no Brasil. No ano de 2002, 565.042 estudantes estavam matriculados na educação profissional técnica de nível médio. Nas redes públicas eram 279.645 matriculados, segundo dados da Sinopse Estatística da Educação Básica 2002 (INSTITUTO NACIONAL DE ESTUDOS E PESQUISAS EDUCACIONAIS ANÍSIO TEIXEIRA, 2003).

Já o Anuário Brasileiro da Educação Básica 2017, por exemplo, aponta que nas redes públicas (não apenas na Federal) as matrículas passaram de 598.176, no ano de 2007 (pode-se ver pequeno aumento entre 2002 e 2007), para 805.178, no ano de
2010. No que se refere à quantidade de matrículas da educação profissional técnica de nível médio em relação ao total de matrículas no ensino médio, as primeiras representavam $11,7 \%$ em 2007 , e chegando a $15,8 \%$ do total de matrículas no ensino médio em 2010. (CRUZ; MONTEIRO, 2017).

A Rede Federal passou por um processo de grande expansão entre 2003 e 2010, quando foram criadas 214 novas unidades. Com isso, passou a contar com 356 unidades no total (REDE FEDERAL DE EDUCAÇÃO PROFISSIONAL CIENTÍFICA E TECNOLÓGICA, 2016). A maior quantidade de instituições educativas foi resultado do "Plano de Expansão da Rede Federal de Educação Tecnológica", que buscava atender ao crescimento da demanda pela educação profissional e tecnológica, por meio de instituições públicas e gratuitas, contemplando a diversificação da oferta de cursos e aumentando o número de vagas (CAIRES; OLIVEIRA, 2016).

Destacamos também, dentro dessa perspectiva da inserção dos jovens e adultos em processos educativos que desenvolvessem as "habilidades" dos mesmos, em sintonia com as recomendações da UNESCO, a criação do Programa Nacional de Integração da Educação Profissional com a Educação Básica na Modalidade de Educação de Jovens e Adultos (Proeja), em 2005, para oferecer oportunidade de estudos e formação profissional às pessoas que não tiveram acesso ao ensino fundamental e médio na idade regular (BRASIL, 2014a).

A adoção das políticas educacionais mencionadas poderia ter representado a concretização da proposta do Governo Lula, pelo menos no primeiro mandato, segundo Oliveira (2009). Nesse sentido, ao esclarecer que o governo anterior, de Fernando Henrique Cardoso, encarnou a lógica do "recurso à racionalidade técnica como meio orientador das políticas sociais" (OLIVEIRA, 2009, p. 197), a autora entende que essa lógica não foi rompida no primeiro mandato de Lula (2003-2006). Esse governo, segundo a autora, "passou a professar a inclusão social no lugar do direito universal à educação" (OLIVEIRA, 2009, p. 197). Essa postura poderia representar, assim, uma continuidade da relação entre as políticas educacionais adotadas no Brasil e as recomendações dos organismos internacionais. 
No primeiro mandato da presidente Dilma Rousseff (2011-2014), por sua vez, como parte do Plano "Brasil sem Miséria”, lançado em 2011, com o objetivo de superar a extrema pobreza até o final de 2014, constava uma organização em três eixos: garantia de renda, inclusão produtiva e acesso a serviços públicos.

Para tanto, Dilma Rousseff criou o Programa Nacional de Acesso ao Ensino Técnico e Emprego (Pronatec), por meio da Lei $\mathrm{n}^{\mathrm{o}} 12.513 / 2011$, cuja a finalidade era ampliar a oferta da educação profissional e tecnológica, por meio de programas, projetos e ações de assistência técnica e financeira, com um dos objetivos voltado para a melhoria da qualidade do ensino médio público, ao articulá-lo com a educação profissional; além de outros, como a expansão e interiorização da oferta de cursos de educação profissional (técnica de nível médio e cursos/programas de formação inicial e continuada ou qualificação profissional) e o fomento e apoio à expansão da rede física de atendimento da educação profissional e tecnológica (BRASIL, 2011a).

Assim, Rousseff implantou a terceira fase do Plano de Expansão da Rede Federal de Educação Profissional, Científica e Tecnológica, que aumentou de 356 para 578 unidades (REDE FEDERAL DE EDUCAÇÃO PROFISSIONAL CIENTÍFICA E TECNOLÓGICA, 2016)

No eixo da inclusão produtiva, o Pronatec teve destaque com a oferta de cursos gratuitos de qualificação para o público de baixa renda (GIAMBIAGI, 2016).

As políticas educacionais descritas contribuíram, de fato, para ampliar a inserção de jovens, inclusive para os que tinham sido excluídos da educação regular (por meio do Programa de Educação de Jovens e Adultos - Proeja) no ensino médio articulado à educação profissional, ainda que não estejam universalizadas essas etapas escolares e que essa "qualificação" nem sempre signifique inserção profissional e econômica, já que o desemprego continua sendo um problema para os jovens, em especial.

No tocante à questão do ensino médio, percebe-se que houve uma mudança considerável nas recomendações dos organismos internacionais entre a década de 1990 e a década de 2000 . No caso da primeira década, destacamos as orientações do re- latório "Prioridades e Estratégias para a Educação", do Banco Mundial (1995). O documento defendia a ideia de que a educação básica deveria ser fornecida gratuitamente, mas a educação secundária e a educação superior deveriam estar sujeitas ao pagamento de taxas. O documento também "traz um viés contra as escolas profissionalizantes e, em particular, contra aquelas de financiamento público", segundo Lauglo (1997, p. 18). A educação profissional é considerada, no relatório, como malsucedida no âmbito da escola, sendo mais bem desenvolvida no local de trabalho.

Já nos anos 2000, em capítulo que integrou um livro publicado pela UNESCO, em 2002, Daniel Filmus trata a educação média como algo cada vez mais necessário e ainda insuficiente diante do mercado de trabalho, no contexto da América Latina, particularmente para ingresso em empregos de qualidade na indústria de produção de bens. Por outro lado, com a diminuição das oportunidades de trabalho, "ao mesmo tempo em que a escola média aumenta a sua importância para o acesso ao trabalho, torna-se cada vez mais insuficiente para assegurar a todos os seus egressos a possibilidade de emprego nos segmentos de qualidade" (FILMUS, 2002).

Essas avaliações sobre a educação secundária nos anos 2000 - notadamente nas manifestações da UNESCO - podem ter influenciado no direcionamento que os governos de Lula e Dilma (20032014) deram às políticas educacionais voltadas para o ensino médio, sobretudo pelo fato de que as preocupações com a formação geral vieram, quase sempre, acompanhadas de defesas de uma articulação entre o ensino secundário e a educação profissional.

As recomendações dos organismos internacionais e as respostas do governo brasileiro podem causar uma impressão de que os anos 2000, no que se refere à inserção de jovens nas instituições escolares de ensino médio (em muitos casos com formação articulada à educação profissional), representam um progresso em relação ao que se observou na década de 1990. Contudo, se lançarmos um olhar mais atento, podemos perceber que essas mudanças foram de forma e não de conteúdo, e também podemos questionar se a oferta de educação pública e gratuita durante um maior período 
de tempo é, em si, garantia de uma inserção profissional e social, ou se tende a se constituir mais como um instrumento para aliviar a tensão social na espera por emprego, mesmo no âmbito de governos democrático-populares.

\section{Influência dos organismos internacionais e as políticas educativas de inclusão no ensino superior}

O Banco Mundial (BM) e a Organização das Nações Unidas para a Educação, a Ciência e a Cultura (UNESCO), com suas principais linhas de orientação, continuam exercendo considerável influência sobre as políticas públicas dos países em desenvolvimento, sobretudo no que se refere às políticas educativas de inclusão no ensino superior no Brasil.

Barreto e Leher (2008), no artigo Do discurso e das condicionalidades do Banco Mundial, a educação superior "emerge" terciária, apresentam uma análise das quatro publicações-chave do Banco Mundial, sendo uma delas em parceria com a UNESCO.

Segundo os autores, em síntese, a primeira publicação, Educação superior: as lições da experiência (BANCO MUNDIAL, 1994), apresenta as seguintes indicações: promover uma associação direta entre redução da pobreza e educação superior, ao mesmo tempo em que reduz esta última a treinamento; promover, a baixo custo, o acesso aos grupos desprivilegiados por meio da educação à distância; instigar o desenvolvimento de instituições não universitárias, cursos flexíveis e de curta duração; e o financiamento privado, com o intuito de atender as qualificações exigidas por uma economia de mercado.

A segunda publicação, Educação superior nos países em desenvolvimento: perigo e promessa (BANCO MUNDIAL, 2000), de autoria da força-tarefa conveniada, aponta para a expansão do número de alunos; a diferenciação crescente dos tipos de instituição; e a revolução do acesso ao conhecimento de forma rápida e de lugares distantes, por meio da tecnologia.

Construindo sociedades do conhecimento: novos desafios para a educação terciária (BANCO
MUNDIAL, 2002), terceira publicação, aponta como tendências: novas demandas do mercado de trabalho e das novas tecnologias; competição entre universidades privadas emergentes; e um mercado internacional de educação terciária.

A quarta e última publicação, Educação permanente na economia global do conhecimento: desafios para os países em desenvolvimento (BANCO MUNDIAL, 2003), traz como indicações: o conhecimento; a expansão de oportunidades de aprendizagem, ou simplesmente o acesso à aprendizagem, ressaltando a importância da tecnologia para transformar a aprendizagem, tornando-a mais flexível e diferenciada para permitir mecanismos de distribuição alternativos.

Diante desses documentos, os autores concluem que todos se referem a uma revolução (da informação ou do conhecimento) e que,

A suposta revolução é funcional à articulação dos discursos da 'sociedade da informação' e da 'globalização' em três sentidos: a) permite uma abordagem 'técnico-científica' das desigualdades econômicas entre os países, reduzindo-as a uma lacuna ou divisor digital; b) legitima intervenções para 'dar assistência aos países que aspiram a superar a lacuna que os separa dos cientificamente avançados' (WORLD BANK, 2002, p. 25); e c) sustenta o rearranjo geoeconômico do planeta [...]. (BARRETO; LEHER, 2008, p. 428).

Essa "revolução" impactou as políticas educativas brasileiras desenvolvidas pelo Ministério da Educação no período de 2003 a 2014, que buscou atender às recomendações dos organismos internacionais, como será demonstrado adiante.

A Declaração Mundial sobre Educação Superior no século XXI: visão e ação (ORGANIZAÇÃO DAS NAÇÕES UNIDAS PARA A EDUCAÇÃO, A CIÊNCIA E A CULTURA, 1998) afirma que há uma demanda sem precedentes e uma grande diversificação na educação superior, apontando os desafios e dificuldades relacionados ao seu financiamento, à igualdade de condições no ingresso e no decorrer do curso de estudos, à melhoria relativa à situação de seu pessoal, ao treinamento com base em habilidades, ao desenvolvimento e manutenção da qualidade no ensino, pesquisa e serviços de extensão, à relevância dos programas oferecidos, à empregabilidade de formandos e egressos, assim 
como o acesso equitativo aos benefícios da cooperação internacional. Ao mesmo tempo, a educação superior está sendo desafiada por oportunidades relativas a tecnologias (ORGANIZAÇÃO DAS NAÇÕES UNIDAS PARA A EDUCAÇÃO, A CIÊNCIA E A CULTURA, 1998).

Nesse sentido, a UNESCO considera que a cooperação entre governos e instituições de educação superior (envolvendo estudantes e suas famílias, professores), o mundo dos negócios e a indústria, os setores públicos e privados da economia, os parlamentos, os meios de comunicação, a comunidade, as associações profissionais e a sociedade, incluindo a perspectiva de intercâmbios internacionais, é o caminho principal para promover o avanço da educação superior.

Além disso, essa Declaração ressalta algumas recomendações contidas nos documentos do Banco Mundial, tais como: a diversificação na educação superior (com novos tipos de instituições com cursos breves, estudo de meio período, horários flexíveis, cursos em módulos, ensino à distância com apoio etc.), por meio de incentivo às iniciativas do setor privado (Art. $8^{\circ}$ ), para complementar os recursos do Estado (Art. $14^{\circ}$ ), entre outras.

A profunda influência das recomendações desses organismos sobre as políticas educacionais no Brasil é perceptível ao se observar os processos de incentivo à privatização e à diferenciação institucional; no financiamento público com a diversificação de fontes de recursos e na própria legislação da área. Nesse sentido, segue uma apresentação das políticas educativas para o ensino superior brasileiro desenvolvidas com o intuito de atender as demandas internacionais.

\section{Políticas educativas de inclusão no ensino superior nos governos Lula (2003-2010) e Dilma (2011-1014)}

O debate sobre a inclusão educacional e suas políticas iniciou-se na década de 1990, a partir da Conferência de "Educação para Todos" realizada na cidade de Jomtien, na Tailândia, que serviu de marco para o delineamento e a execução de políticas educacionais no mundo inteiro (FUNDO DAS NAÇÕES UNIDAS PARA A INFÂNCIA, 1990). As propostas, tais como o atendimento e garantia de acesso e permanência à Educação Básica, por meio de satisfação das necessidades básicas de aprendizagem de crianças, jovens e adultos de diferentes grupos e culturas, foram aprofundadas com a Declaração de Salamanca, em 1994, a qual tem a finalidade de fornecer diretrizes básicas para a formulação e reforma de políticas e sistemas educacionais guiados pelo princípio da inclusão social, expressando o direito à educação e à aprendizagem. Ambas declarações divulgam os principais preceitos que orientam as políticas sociais e educacionais, ditas como políticas de inclusão (CONFERÊNCIA MUNDIAL SOBRE EDUCAÇÃO ESPECIAL, 1994).

No Brasil, é o Programa de Governo de Lula da Silva (2002), denominado "Um Brasil para Todos: crescimento, emprego e inclusão social", que sinaliza uma mudança de ordem conceitual e política no campo educacional ao situá-lo como parte das políticas de inclusão social. A educação é compreendida como "um instrumento de promoção da cidadania e, sobretudo nos dias de hoje, instrumento fundamental para o desenvolvimento e a inserção competitiva de qualquer nação no mundo" (COMITÊ LULA PRESIDENTE, 2002, p. 44), e foi estabelecida como prioridade de investimentos em "Todos os elos educacionais, da creche a pós-graduação" (COMITÊ LULA PRESIDENTE, 2002, p. 46). Em relação à educação superior, o Programa apresenta como tarefa inadiável "a ampliação significativa das vagas nas universidades públicas e a reformulação do sistema de crédito educativo vigente" (COMITÊ LULA PRESIDENTE, 2002, p. 46).

No que se refere à educação superior, o Plano de Desenvolvimento da Educação (PDE) $)^{1}$ do referido governo define os seguintes princípios:

i) expansão da oferta de vagas, dado ser inaceitável que somente $11 \%$ de jovens, entre 18 e 24 anos, tenham acesso a esse nível educacional, ii) garantia de qualidade, pois não basta ampliar, é preciso

1 O PDE “foi aprovado pelo Presidente da República Luiz Inácio Lula da Silva e pelo Ministro da Educação Fernando Haddad em 24 de abril de 2007, com o objetivo de melhorar a Educação no País, em todas as suas etapas, em um prazo de quinze anos. Este prevê várias ações que visam identificar e solucionar os problemas que afetam diretamente a Educação brasileira, mas vai além por incluir ações de combate a problemas sociais que inibem o ensino e o aprendizado com qualidade" (EDUCACIONAL, 2017). Este foi o primeiro plano deste tipo, no governo Lula. 
fazê-lo com qualidade, iii) promoção de inclusão social pela educação, minorando nosso histórico de desperdício de talentos, considerando que dispomos comprovadamente de significativo contingente de jovens competentes e criativos que têm sido sistematicamente excluídos por um filtro de natureza econômica, iv) ordenação territorial, permitindo que ensino de qualidade seja acessível às regiões mais remotas do País, e v) desenvolvimento econômico e social, fazendo da educação superior, seja enquanto formadora de recursos humanos altamente qualificados, seja como peça imprescindível na produção científico-tecnológica, elemento-chave da integração e da formação da Nação. (BRASIL, 2007, p. 25).

As principais políticas, ações e programas educacionais previstos pelo PDE (BRASIL, 2007a), no âmbito da educação superior, são: o Plano de Reestruturação e Expansão das Universidades Federais (REUNI); o Plano Nacional de Assistência Estudantil (PNAES), com o intuito de consolidar o REUNI; o Programa Universidade para Todos (PROUNI); o Fundo de Financiamento ao Estudante do Ensino Superior (FIES); e a Universidade Aberta do Brasil (UAB).

O FIES, instituído pela Medida Provisória $n^{\circ}$ 1.827, de 27 de maio de 1999, substituiu o Programa Crédito Educativo, implantado em 1976, e foi convertido na Lei $\mathrm{n}^{\circ} 10.260$, em 12 de julho de 2001. Destinado a financiar a graduação na educação superior de estudantes matriculados em instituições privadas, foi ampliado e facilitado no Governo Lula, garantindo a milhares de pessoas a possibilidade de frequentar um curso superior. Em 2003, o FIES realizou 276.163 mil contratos, em 2014 o programa atingiu a marca de 1,9 milhão de novos estudantes beneficiados (MINISTÉRIO DA EDUCAÇÃO, 2014).

O PROUNI é um programa de expansão de vagas na educação superior promovido pelo governo Lula, criado em 10/09/2004, por meio da Medida Provisória $n^{0} 213$, e institucionalizado pela Lei $\mathrm{n}^{\mathrm{o}} 11.096$, de 13 de janeiro de 2005, destinado à concessão de bolsas de estudos integrais e parciais (50\% e $25 \%)$ para instituições privadas de ensino superior; em contrapartida, as Instituições de Ensino Superior (IES) têm isenção fiscal. No período de 2005 a 2014, mais de 2,2 milhões de estudantes de baixa renda tiveram acesso ao ensino superior por meio das bolsas do PROUNI, sendo mais de 1,2 milhão de bolsas integrais e 930,103 mil bolsas parciais (BRASIL, 2015a)

A implementação do Sistema Universidade Aberta do Brasil (UAB) ocorreu por meio do Decreto $\mathrm{n}^{\mathrm{o}}$ 5.800, de 2006 (BRASIL, 2006), com a finalidade de ampliar o acesso à educação superior no país, por meio da modalidade a distância. $\mathrm{Ou}$ seja, uma rede de educação a distância constituída dentro das universidades federais, voltada para a oferta de cursos de licenciatura. Com essa medida, o Brasil passou de 49.911 matrículas em cursos de graduação a distância em 2003, para 1.341.842 matrículas em 2014, ainda que as matrículas de cursos a distância sejam predominantes da rede privada, mesmo com a criação do programa UAB, conforme a Sinopse Estatística da Educação Superior 2014 (INSTITUTO NACIONAL DE ESTUDOS E PESQUISAS EDUCACIONAIS ANÍSIO TEIXEIRA, 2015).

O REUNI foi instituído pelo Decreto $\mathrm{n}^{\circ}$ 6.096, de 24 de abril de 2007, com o objetivo de

$\S 1^{\circ}[\ldots]$ criar condições para a ampliação do acesso e permanência na educação superior, no nível de graduação, pelo melhor aproveitamento da estrutura física e de recursos humanos existentes nas universidades federais" (Art. $1^{\circ}$ ). Com a principal meta de "[...] elevação gradual da taxa de conclusão média dos cursos de graduação presenciais para noventa por cento e da relação de alunos de graduação em cursos presenciais por professor para dezoito, ao final de cinco anos, a contar do início de cada plano. BRASIL, 2007b).

Assim, o programa busca não só garantir o ingresso dos estudantes na educação superior, mas a conclusão efetiva dos cursos pelos estudantes. De acordo com o Balanço Social SESu 2003-2014, foram criadas 18 novas universidades federais entre 2003 e 2014 . Ou seja, um salto de 45 para 63 universidades federais; e de 148 campus para 321, no período de 2002 a 2014 (BRASIL, 2014b)

O Programa Nacional de Assistência Estudantil (PNAES) foi criado pelo Decreto $\mathrm{n}^{\circ} 7.234$, de 2010 (BRASIL, 2010), com os objetivos de: promover a permanência dos jovens na educação superior pública, viabilizar a igualdade de oportunidades entre todos estudantes e contribuir para a promoção da inclusão social pela educação. O PNAES 
é apresentado como instrumento de consolidação do Reuni, constituindo-se apoio fundamental aos estudantes que se deslocam de outras regiões e cidades e que não possuem condições financeiras para permanecer nas IFES. O volume de benefícios concedido por meio do programa para as ações que contemplam a moradia estudantil, a alimentação, o transporte, a assistência à saúde, a inclusão digital, a cultura, o esporte, a creche e o apoio pedagógico, passou de 198.000 em 2008, para 1.078.000 em 2012 (BRASIL, 2012b).

A política para educação superior do Governo Dilma Rousseff (2011-2014) demonstrou a continuidade do programa do Governo Lula da Silva, em relação à expansão da rede federal e à importância de novos papéis para as universidades consoantes às demandas econômicas, inclusive o processo da internacionalização da educação superior. Segundo Oliveira (2013), em agosto de 2011, a presidenta Dilma Rousseff anunciou a continuidade do Plano de Expansão da Rede Federal de Educação Superior e Profissional e Tecnológica, mediante a construção de quatro novas universidades federais, novos campi universitários e Institutos Federais Tecnológicos.

O governo Dilma propôs-se manter e ampliar os programas iniciados no governo Lula e criou outros, cabendo mencionar: o Programa Ciência sem Fronteiras (CsF), criado pelo Decreto $n^{\circ} 7.642$, de 13 de dezembro de 2011 (BRASIL, 2011b), para incentivar a formação acadêmica no exterior e também a atração de jovens talentos estrangeiros para atuação em áreas consideradas prioritárias, ${ }^{2}$ o qual, de acordo com dados da Coordenação de Aperfeiçoamento de Pessoal de Nível Superior (CAPES) e do Conselho Nacional de Desenvolvimento Científico e Tecnológico (CNPq), concedeu, entre 2011 e 2014, 101.446 bolsas de estudo (BRASIL, 2015b).

Outra iniciativa foi a criação da Lei ${ }^{\circ} 12.711$, de 29 de agosto de 2012 (BRASIL, 2012a), Lei de

2 As áreas contempladas são: Engenharias e demais áreas tecnológicas; Ciências Exatas e da Terra; Biologia, Ciências Biomédicas e da Saúde; Computação e Tecnologias da Informação; Tecnologia Aeroespacial; Fármacos; Produção Agrícola Sustentável; Petróleo, Gás e Carvão Mineral; Energias Renováveis; Tecnologia Mineral; Biotecnologia; Nanotecnologia e Novos Materiais; Tecnologias de Prevenção e Mitigação de Desastres Naturais; Biodiversidade e Bioprospecção; Ciências do Mar; Indústria Criativa (voltada a produtos e processos para desenvolvimento tecnológico e inovação); Novas Tecnologias de Engenharia Construtiva e Formação de Tecnólogos (CIÊNCIA SEM FRONTEIRAS, 2016).
Cotas, que dispõe sobre o ingresso nas universidades federais e nas instituições federais de ensino técnico de nível médio. Com isso, "As instituições federais de educação superior vinculadas ao Ministério da Educação reservarão, em cada concurso seletivo para ingresso nos cursos de graduação, por curso e turno, no mínimo 50\% (cinquenta por cento) de suas vagas para estudantes que tenham cursado integralmente o ensino médio em escolas públicas" (BRASIL, 2012a). Segundo a Secretaria de Políticas de Promoção da Igualdade Racial (Seppir), a medida abriu aproximadamente 150 mil vagas para negros, e o percentual de vagas para cotistas aumentou para $40 \%$ em 2014 , isto é, as metas estão sendo atingidas antes do prazo previsto pelas instituições federais de ensino que participam do sistema.

\section{Considerações}

Este artigo se propôs saber qual a resposta brasileira às recomendações internacionais em relação à inclusão de parcelas da população jovem no ensino médio e superior.

Os documentos referidos, as políticas descritas e os dados apresentados apontam para o atendimento quase integral às recomendações daqueles organismos, apesar do discurso político-ideológico contrário a essa perspectiva, no âmbito de governos democrático populares - constatação que não é, em si, negativa ou positiva, posto que há um avanço significativo no número de jovens que passaram a ter acesso e concluir tanto o ensino médio, como o ensino superior no Brasil.

Entretanto, questões que permanecem, em relação ao alcance dessas políticas, dizem respeito a saber até que ponto os jovens que foram qualificados pelos programas oferecidos - especialmente no ensino médio, mas também no superior - vêm conseguindo uma inserção também qualificada no mercado de trabalho e na vida social?

Por outro lado, ainda que seja inegável a importância dessas políticas de inclusão para a educação superior, na qual tem havido forte incentivo à participação da iniciativa privada, contraditoriamente, parece maior a contribuição para o aumento da margem de lucro das instituições empresariais que promovem esse nível de ensino. 
Pesquisas são necessárias não só para verificar os dados em séries históricas - que tendem a um aumento significativo -, mas também para compreender em que medida as questões político-ideológicas são atravessadas pela lógica dos organismos internacionais, em defesa da ordem vigente sob o capitalismo tardio (ADORNO, 1986) e escamoteiam um atendimento maior aos grandes conglomerados educacionais e menor à inclusão efetiva de parcelas da população em melhores condições de competir no mercado de trabalho e lidar com os desafios da vida social.

\section{REFERÊNCIAS}

ADORNO, Theodor W. Capitalismo tardio ou sociedade industrial? In: COHN, Gabriel (Org.). Theodor W. Adorno. São Paulo: Ática. 1986. p. 63-75.

BANCO MUNDIAL. Higher education: the lessons of experience. 1994. Disponível em: <http://documents. worldbank.org/curated/en/303461468328502540/pdf/multi-page.pdf $>$. Acesso em: 02 maio 2017.

La enseñanza superior: las lecciones derivadas de la experiencia (El desarrollo en la práctica). Washington, D.C: BIRD/Banco Mundial, 1995.

Higher education in developing countries: peril and promise. 2000. Disponível em: $<$ http://documents. worldbank.org/curated/pt/345111467989458740/pdf/multi-page.pdf $>$. Acesso em: 03 maio 2017.

Constructing knowledge societies: new challenges for tertiary education. 2002. Disponível em: <http:// documents.worldbank.org/curated/en/732991468143369052/pdf/249730PUB0REPL00Knowledge0Societies.pdf>. Acesso em: 03 maio 2017.

. Lifelong learning in the global knowledge economy: challenges for developing countries. 2003. Disponível

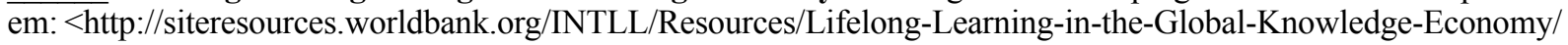
lifelonglearning_GKE.pdf $>$. Acesso em: 03 maio 2017.

BARRETO, Raquel Goulart; LEHER, Roberto. Do discurso e das condicionalidades do Banco Mundial, a educação superior "emerge” terciária. In: Revista Brasileira de Educação, Rio de Janeiro, v. 13, n. 39, set./dez. 2008. Disponível em: < http://dx.doi.org/10.1590/S1413-24782008000300002>. Acesso em: 20 jun. 2017.

BRASIL. Presidência da República. Casa Civil. Decreto no 5.800, de 08 de junho de 2006. Dispõe sobre o Sistema Universidade Aberta do Brasil - UAB. Brasília, DF, 2006. Disponível em: <http://www.planalto.gov.br/ ccivil_03/_ato2004-2006/2006/decreto/d5800.htm>. Acesso em: 02 abr. 2017.

Ministério da Educação. Plano de Desenvolvimento da Educação - razões, princípios e programas. Brasília, DF, 2007a. Disponível em: <http://portal.mec.gov.br/arquivos/livro/livro.pdf>. Acesso em: 06 maio 2017.

Presidência da República. Casa Civil. Decreto no 6.096, de 24 de abril de 2007. Institui o Programa de Apoio a Planos de Reestruturação e Expansão das Universidades Federais - REUNI. Brasília, DF, 2007b. Disponível em: <http://www.planalto.gov.br/ccivil_03/_ato2007-2010/2007/decreto/d6096.htm>. Acesso em: 02 jun. 2017.

. Presidência da República. Casa Civil. Decreto no 7.234, de 19 de julho de 2010. Dispõe sobre o Programa Nacional de Assistência Estudantil - PNAES. Brasília, DF, 2010. Disponível em: <http://www.planalto.gov.br/ ccivil_03/Ato2007-2010/2010/Decreto/D7234.htm>. Acesso em: 02 jun. 2017.

Presidência da República. Casa Civil. Lei no 12.513, de 26 de outubro de 2011. Institui o Programa Nacional de Acesso ao Ensino Técnico e Emprego (Pronatec); altera as Leis no 7.998, de 11 de janeiro de 1990, que regula o Programa do Seguro-Desemprego, o Abono Salarial e institui o Fundo de Amparo ao Trabalhador (FAT), no 8.212, de 24 de julho de 1991, que dispõe sobre a organização da Seguridade Social e institui Plano de Custeio, no 10.260, de 12 de julho de 2001, que dispõe sobre o Fundo de Financiamento ao Estudante do Ensino Superior, e no 11.129, de 30 de junho de 2005, que institui o Programa Nacional de Inclusão de Jovens (ProJovem); e dá outras providências. Brasília, DF, 2011a. Disponível em: <http://www.planalto.gov.br/ccivil_03/_ato2011-2014/2011/lei/ 112513.htm>. Acesso em: 20 nov. 2016.

Presidência da República. Casa Civil. Decreto no 7.642, de 13 de dezembro de 2011. Institui o Programa Ciência sem Fronteiras. Brasília, DF, 2011b. Disponível em: $<\underline{\text { https://presrepublica.jusbrasil.com.br/legisla- }}$ cao/1030355/decreto-7642-11>. Acesso em: 04 jun. 2017. 
Presidência da República. Casa Civil. Lei no 12.711, de 29 de agosto de 2012. Dispõe sobre o ingresso nas universidades federais e nas instituições federais de ensino técnico de nível médio e dá outras providências. Brasília, DF, 2012a. Disponível em: < http://www.planalto.gov.br/ccivil_03/_ato2011-2014/2012/Lei/L12711.htm>. Acesso em: 07 jul. 2015.

. Ministério da Educação. Análise sobre a Expansão das Universidades Federais 2003 a 2012. Brasília, DF, 2012b. Disponível em: $<$ http://portal.mec.gov.br/index.php?option=com_docman\&view=download\&alias=12386-analise-expansao-universidade-federais-2003-2012-pdf\&Itemid=30192> . Acesso: 05 jul. 2017.

Ministério da Educação. Relatório Educação para Todos no Brasil 2000-2015 - Versão Preliminar. Brasília, DF, 2014a. Disponível em: <http://portal.mec.gov.br/docman/junho-2014-pdf/15774-ept-relatorio-06062014/ file>. Acesso em: 28 maio 2017.

Ministério da Educação. Secretaria de Educação Superior. A democratização e expansão da educação superior no país 2003-2014. Brasília, DF, 2014b. Disponível em: $<$ http://portal.mec.gov.br/index.php?option=com docman\&view=download\&alias=16762-balanco-social-sesu-2003-2014\&category_slug=dezembro-2014pdf\&Itemid=30192>. Acesso em: 05 jul. 2017.

BRASIL. Ministério da Educação. Programa Universidade para Todos (PROUNI). Bolsas ofertadas por ano. Brasília, DF, 2015a. Disponível em: <http://prouniportal.mec.gov.br/images/pdf/Representacoes_graficas/bolsas_ofertadas_ano.pdf $>$. Acesso em: 07 jun. 2017.

Ministério da Educação. Coordenação de Aperfeiçoamento de Pessoal de Nível Superior (CAPES). Capes e CNPq apresentam avaliação preliminar do Ciência sem Fronteiras. 2015b. Disponível em: <http://www.capes. gov.br/sala-de-imprensa/noticias/7583-capes-e-cnpq-apresentam-avaliacao-preliminar-do-ciencia-sem-fronteiras $>$. Acesso em: 07 jun. 2017.

CAIRES, Vanessa Guerra; OLIVEIRA, Maria Auxiliadora Monteiro. Educação profissional brasileira: da colônia ao PNE 2014-2024. Petrópolis, RJ: Vozes, 2016.

CIÊNCIA SEM FRONTEIRAS. Áreas contempladas. Disponível em: $<\underline{\text { http://www.cienciasemfronteiras.gov.br/ }}$ web/csf/areas-contempladas $>$. Acesso em: 07 ago. 2016.

COMITÊ LULA PRESIDENTE. Programa de Governo 2002. Disponível em: < $\underline{\text { http://www2.fpa.org.br/uploads/ }}$ programagoverno.pdf $>$. Acesso em: 05 jul. 2017.

CONFERÊNCIA MUNDIAL SOBRE EDUCAÇÃO ESPECIAL. Declaração de Salamanca - Sobre Princípios, Políticas e Práticas na Área das Necessidades Educativas Especiais. Salamanca, 1994.

CRUZ, Priscila; MONTEIRO, Luciano (Org.). Anuário Brasileiro da Educação Básica 2017. São Paulo: Todos Pela Educação/Moderna, 2017. Disponível em: <https://www.todospelaeducacao.org.br//arquivos/biblioteca/anuario_brasileiro_da_educacao_basica_2017_com_marcadores.pdf $>$. Acesso em: 19 ago. 2017.

EDUCACIONAL. Plano de Desenvolvimento da Educação - PDE. Disponível em: $<$ http://www.educacional. com.br/legislacao/leg_i.asp>. Acesso em: 07 jul. 2017.

FILMUS, Daniel. A educação média diante do mercado de trabalho: cada vez mais necessária, cada vez mais insuficiente. In: BRASLAVSKY, Cecília (Org.). Educação secundária: mudança ou imutabilidade? Tradução de Francisco Baltar e Joaquim Ozório. Brasília, DF: UNESCO, 2002. p. 127-186.

FUNDO DAS NAÇÕES UNIDAS PARA A INFÂNCIA (UNICEF). Conferência de "Educação para todos". Jomtien, 1990. Disponível em: < https://www.unicef.org/brazil/pt/resources 10230.htm>. Acesso em: 02 maio 2017.

GIAMBIAGI, Fabio. Fim de ciclo: o governo Dilma (2011-2015). GIAMBIAGI, Fabio. Et al (Org.). Economia brasileira contemporânea (1945-2015). 3. ed. Rio de Janeiro: Elsevier, 2016. p. 239-275.

INSTITUTO NACIONAL DE ESTUDOS E PESQUISAS EDUCACIONAIS ANÍSIO TEIXEIRA(INEP). Sinopse Estatística da Educação Básica 2002. Brasília, DF, 2003. Disponível em: <http://portal.inep.gov.br/sinopses-estatisticas-da-educacao-basica>. Acesso em: 27 ago. 2017.

Sinopse Estatística da Educação Superior 2014. Brasília, DF, 2015. Disponível em: $<$ http://portal.inep.

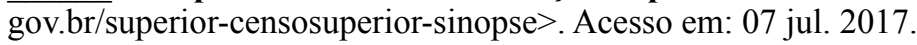

Sinopse Estatística da Educação Básica 2016. Brasília, DF, 2017. Disponível em: $<$ http://portal.inep.

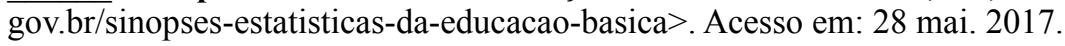


LAUGLO, Jon. Crítica às prioridades e estratégias do Banco Mundial para a educação. Tradução de Dagmar M. L. Zibas. Cadernos de Pesquisa, n. 100, p. 11-36, mar. 1997. Disponível em: <http://publicacoes.fcc.org.br/ojs/ index.php/cp/article/viewFile/765/777>. Acesso em: 20 out. 2017.

OLIVEIRA, Dalila Andrade. As políticas educacionais no governo Lula: rupturas e permanências. RBPAE, v. 25, p. 197-209, maio/ago. 2009. Disponível em: <http://seer.ufrgs.br/rbpae/article/view/19491/11317>. Acesso em: 13 ago. 2017.

OLIVEIRA, João Ferreira de. Os papéis sociais e a gestão das universidades federais no Brasil. In: SIMPÓSIO DA ANPAE, 26., 2013, Recife. Anais eletrônicos... Recife: ANPAE, 2013. Disponível em: <http://www.anpae.org.br/ simposio26/1 comunicacoes/joaoFerreira-ComunicacaoOral-int.pdf $>$. Acesso em: 07 maio 2017.

ORGANIZAÇÃO DAS NAÇÕES UNIDAS PARA A EDUCAÇÃO, A CIÊNCIA E A CULTURA (UNESCO). Educação para Todos: o compromisso de Dakar. Brasília, DF: UNESCO/CONSED/Ação Educativa, 2001.

Declaración mundial sobre la educación superior en el siglo XXI: visión y acción. Paris, 1998.

REDE FEDERAL DE EDUCAÇÃO PROFISSIONAL, CIENTÍFICA E TECNOLÓGICA. Expansão da Rede Federal. Brasília, DF, 2016. Disponível em: $<$ http://redefederal.mec.gov.br/expansao-da-rede-federal $>$. Acesso em: 16 nov. 2016.

Recebido: 05/09/2017

Aprovado: 26/10/2017 